\title{
The Experience of Patients with COVID-I9 in China: An Interpretative Phenomenological Analysis
}

\author{
Yanbo Wang' \\ Xiao $\mathrm{Pan}^{2}$ \\ Yonghai Bai (iD ${ }^{2}$ \\ 'Shanghai Pudong New Area Mental \\ Health Center, Tongji University School \\ of Medicine, Shanghai, 200I22, People's \\ Republic of China; ${ }^{2}$ Department of \\ Medical Psychology, Changzheng \\ Hospital, Naval Medical University, \\ Shanghai, 200003, People's Republic of \\ China
}

\begin{abstract}
Aim: The present study examined the experiences of patients diagnosed with COVID-19 to better understand their concerns and inspiration and provide better care.

Methods: Semistructured interviews were performed with 10 COVID-19 patients from the Optical Valley Branch of Maternity and Child Healthcare Hospital of Hubei Province. Interviews were recorded on audiotape and transcribed verbatim. Transcripts were analysed using an interpretative phenomenological analysis.

Results: Four superordinate themes emerged: psychological distress caused by COVID-19 uncertainty, ethical dilemmas that will be faced after returning to the family and society, resources to cope with COVID-19, and event-related growth experience.

Conclusion: Patients with COVID-19 were generally at high risk of having mental and social health challenges. Although the epidemic obviously affected their overall health, which led to their negative emotions or concerns, it also had a positive effect, such as viewing their relationship with families or others more positively and having more thoughts and outlooks on life. The study prompted medical staff to take their time listening to patients and pay more attention to specific psychological and social health problems in future care. Keywords: patients' experience, COVID-19, adaptation and growth, interpretative phenomenological analysis
\end{abstract}

\section{Introduction}

The first outbreak of coronavirus disease 19 (COVID-19) occurred in Wuhan, China, in December 2019 and quickly spread throughout China and internationally. ${ }^{1}$ COVID-19 has been linked to over 97 million infections and 2.1 million deaths in 213 countries or areas as of January $24,2021 .^{2}$ After a year of fighting COVID-19, three COVID-19 vaccines were developed, and national regulatory authorities authorized their use by the end of December 2020 and the use of other candidates soon thereafter. ${ }^{3}$ However, as the announced first outbreak area, Wuhan suffered the most during the early months, and no specific treatments or vaccines were available for the first group of patients with COVID-19. Isolation and self-healing or supportive care were primarily performed for patients with mild and moderate illnesses, and intensive care and ventilator support were primarily provided to critically ill patients. ${ }^{4,5}$

The COVID-19 pandemic and its consequences have three hallmark characteristics of traumatic events: unpredictability, uncontrollability, and the threat of death or serious injury, as described in the ICD-11 (International Classification of Diseases) and DSM-5
Correspondence: Yonghai Bai Department of Medical Psychology, Changzheng Hospital, Naval Medica University, Shanghai, 200003, People's Republic of China

Tel +86-2I- 81885066

Email baiyonghail79@I26.com 
(Diagnostic and Statistical Manual of Mental Disorders) diagnostic criteria. Well-established evidence shows that exposure to traumatic stressors exerts profound effects on long-term mental and behavioural health. ${ }^{6}$ The COVID-19 pandemic and the public health measures critical to containing it were associated with three factors that are deleterious to mental health: fear, social isolation and stigma. ${ }^{7}$ Social media exposure was also a risk factor for increased anxiety during the COVID-19 outbreak due to increased access to online content. Quarantine and isolation are used to protect people's physical health when a risk of infectious diseases exists, but the mental health implications of the people experiencing these restrictions must be considered. ${ }^{8}$ Stigma also increases the risk of poor mental health, which was observed in the SARS outbreak. ${ }^{9}$ Experiences from previous epidemics, such as SARS in 2003 and H1N1 in 2009, showed that patients with a confirmed diagnosis of the disease causing the epidemic faced physical suffering and difficulties in psychological or social aspects, which may be even more obvious and serious than the physical illness, especially for patients in a noncritical status. ${ }^{10-12}$ Patients, caregivers, and health-care workers are particularly at risk of trauma responses and would be well served by trauma-informed care practices to minimize immediate and long-term psychological distress. ${ }^{13}$ Many studies assessed depression, anxiety, stress, and other forms of distress in the general population and health care workers. ${ }^{14}$ However, an in-depth examination and discussion of patients' perspectives and real feelings of their experiences during the process of contracting the disease associated with the epidemic are lacking. The present study examined how confirmed patients who were receiving treatments and supportive care in the hospital perceived their experiences with COVID-19, especially their experience of adaptation and growth.

\section{Methods}

\section{Sample and Setting}

The study recruited participants in the Optical Valley Branch of Maternity and Child Healthcare Hospital of Hubei Province in Wuhan, China. This is a specialist hospital that has not been completed and was transformed to one of the designated hospitals for admitting patients with COVID-19 during the outbreak in Wuhan. The hospital has 12 sick bays and more than 700 beds, and it began admitting patients with COVID-19 beginning on February 21, 2020. All of the patients were cleared on April 7, 2020. YH Bai worked temporarily in the research hospital to support the fight against COVID-19 in Wuhan during this time. The present study was performed during March 2020, and a convenience sampling method was used to recruit hospitalized patients in one of the sick bays of the hospital. The inclusion criteria were patients who were diagnosed with COVID-19 (mild or usual type), ${ }^{15}$ had clear thoughts and fluent expression, and had some characteristics or background that may have led to some unique experiences. The exclusion criteria included patients who did not speak Mandarin, patients over 60 years old, and anyone who refused to participate in the study. Ten participants were interviewed. Participants' characteristics are shown in Table 1. The ages of the participants ranged from 26 to 54 years, with a mean age of $43.8 \pm 9.53$ years. Half of the participants were male, and half were female. The duration of infection since their diagnosis ranged from 17 to 54 days. Participants received regular therapy or stem cell therapy. Four participants infected their family members. Confidentiality was maintained using "P1, P2 „. P10" to identify participants.

\section{Procedure}

The study was performed in accordance with the Declaration of Helsinki, and the ethics panel of the Medical Association of Changzheng Hospital approved this study (No. 2020SL010). All patients provided informed consent for their case details and anonymised responses to be published. They were clearly informed that they had the right to refuse or withdraw from the study at any time and that it would not affect their treatments and care. The purpose, content, process, and principle of confidentiality of the study were introduced to the potential participants in accordance with standardised instructions. Informed consent was obtained when they agreed to participate in the study. Interviews were performed in a private room, and each interview lasted approximately 1 hour. The interviews were audio-recorded with the participants' permission and transcribed verbatim. Dr. Bai performed the interviews to ensure that the same focus and techniques were used and to maintain the interview quality. YB Wang transcribed all audio recordings into texts within 48 hours after each interview. Each interview was performed until the experiences of the patients were well explained, and no new information was available. When no new information was forthcoming, saturation was considered to have been reached. A semistructured interview schedule was used as a loose guideline during interviews: 
Table I Participants' Information

\begin{tabular}{|c|c|c|c|c|c|c|c|}
\hline No. & Gender & $\begin{array}{c}\text { Age } \\
\text { (Years) }\end{array}$ & Occupation & Treatment & $\begin{array}{l}\text { Duration Since } \\
\text { Diagnosis (Days) }\end{array}$ & $\begin{array}{l}\text { Family } \\
\text { Infection }\end{array}$ & Other Characteristics \\
\hline $\mathrm{PI}$ & Female & 48 & $\begin{array}{l}\text { Financial } \\
\text { executive }\end{array}$ & $\begin{array}{l}\text { Regular } \\
\text { therapy }\end{array}$ & 22 & None & Aggregated infection \\
\hline P2 & Male & 41 & $\begin{array}{l}\text { Technical } \\
\text { staff }\end{array}$ & $\begin{array}{l}\text { Stem cell } \\
\text { therapy }\end{array}$ & 54 & None & $\mathrm{N} / \mathrm{A}$ \\
\hline P3 & Female & 54 & Entrepreneur & $\begin{array}{l}\text { Stem cell } \\
\text { therapy }\end{array}$ & 17 & A daughter & $N / A$ \\
\hline P4 & Male & 50 & $\begin{array}{l}\text { Supermarket } \\
\text { staff }\end{array}$ & $\begin{array}{l}\text { Regular } \\
\text { therapy }\end{array}$ & 48 & None & Repeated positive nucleic acid tests \\
\hline P5 & Male & 50 & Worker & $\begin{array}{l}\text { Regular } \\
\text { therapy }\end{array}$ & 50 & $\begin{array}{l}\text { Wife and } \\
\text { father }\end{array}$ & $\begin{array}{l}\text { Both his wife and father died from COVID- } \\
\qquad 19\end{array}$ \\
\hline P6 & Male & 52 & $\begin{array}{l}\text { Sales } \\
\text { executive }\end{array}$ & $\begin{array}{l}\text { Stem cell } \\
\text { therapy }\end{array}$ & 43 & $\begin{array}{l}\text { Both } \\
\text { Parents }\end{array}$ & $\begin{array}{c}\text { The father died from COVID-19 and lived in } \\
\text { the same ward with the mother }\end{array}$ \\
\hline P7 & Female & 26 & Waitress & $\begin{array}{l}\text { Regular } \\
\text { therapy }\end{array}$ & 41 & None & Repeated positive nucleic acid tests \\
\hline P8 & Male & 49 & $\begin{array}{l}\text { Car } \\
\text { mechanic }\end{array}$ & $\begin{array}{l}\text { Regular } \\
\text { therapy }\end{array}$ & 38 & Wife & $\begin{array}{l}\text { Lived in the same sick bay with his wife for } \\
\text { one day }\end{array}$ \\
\hline P9 & Female & 36 & $\begin{array}{l}\text { Private } \\
\text { institution }\end{array}$ & $\begin{array}{l}\text { Regular } \\
\text { therapy }\end{array}$ & 40 & None & $\begin{array}{l}\text { Lay Buddhist, repeated positive nucleic acid } \\
\text { tests }\end{array}$ \\
\hline PIO & Female & 32 & $\begin{array}{l}\text { Training } \\
\text { director }\end{array}$ & $\begin{array}{l}\text { Regular } \\
\text { therapy }\end{array}$ & 26 & None & Postpartum, diagnosed during pregnancy \\
\hline
\end{tabular}

1. Could you please give a brief introduction of yourself and narrate your experiences of illness and treatments?

2. What are your emotions in this process?

3. Did any of your family members get infected, and what is their situation?

4. What are the positive/negative effects of the infection on your life and your family?

5. Could you please talk about your future plans or thoughts?

6. What is your opinion on the doctor-patient relationship now?

\section{Data Analysis}

The researcher carefully interpreted and made inferences from individual accounts, helped by an inductive, iterative, and idiographic stance with a focus on the particular rather than the general to access the individuals' experiences (De Visser and Smith, 2006; Smith and Osborn, 2008). ${ }^{16,17}$ Transcribed interviews were analysed according to interpretative phenomenological analysis (IPA) processes and procedures as defined by Smith and Osborn. ${ }^{17}$ The transcript was read several times, and the left-hand margin was used to annotate interesting or significant items mentioned by the respondent. The second stage involved returning to the transcript afresh and using the right-hand margin to transform the initial notes and ideas into more concise phrases, which moved the response to a slightly higher level of abstraction to invoke more psychological terminology. This transformation of initial notes into themes continued throughout the transcript. The third stage consisted of further data reduction by establishing connections between the preliminary themes and clustering the themes appropriately. Finally, a table was produced that showed each higher-order theme and the subthemes that it comprised. The first and corresponding authors developed the initial codes and potential themes. The first and corresponding authors reviewed and refined the themes via an iterative process until a consensus was reached on the final thematic map. 


\section{Results}

Four superordinate themes emerged as important aspects of the adjustment and growth of the participants with COVID-19, each with several subthemes. Although some overlap between these themes occurred, they appeared sufficiently distinct for separate identification. These themes and subthemes are discussed in detail below.

\section{Theme I Psychological Distress Caused by COVID-19 Uncertainty}

Uncertainty refers to epistemic situations involving imperfect or unknown information. COVID-19 was a novel virus for the world, and patients with the disease and clinical medical experts knew very little about it. Information on its spread, prevention, diagnosis, treatments, and prognosis remain uncertain, which imposes great psychological stress on patients because they are surrounded by a large amount of uncertain information. Most participants expressed their negative emotional experiences after diagnosis. Emotions, such as self-doubt, anxiety, and fear related to the uncertainty of COVID-19, often appeared involuntarily throughout the entire diagnostic and treatment processes.

\section{Subtheme I Self-Doubt During Diagnosis and Treatment}

The strong sense of uncertainty about COVID-19 and a patient's physical health status often made them fall into selfdoubt ruminations. At the initial stage of diagnosis, many participants (P1, P2, P7, and P10) were trapped in reflection on certain issues: "How I was infected?" and "Why were their symptoms worse than other patients?" Participants 1 and 7 noted:

Why doesn't anyone else get this disease? I have been at home and haven't been anywhere. Why did I get this disease? Is it because I'm not as good as others? (P7)

I knew that all of my (infected) colleagues might be crossinfected in the office. Their symptoms were all mild. Why was it that only I had high temperature and severe symptoms? I do not know why I was in such a (severe) situation. Am I weaker than them? (P1)

During the treatment process, some participants (such as P4 and P9) experienced recurring symptoms, and nucleic acid testing was repeatedly positive. As a result, these patients were troubled by a strong sense of uncertainty.
They had doubts about their health condition and possibility of cure. As P4 described:

It was still positive after carrying out 15 nucleic acid detections. I can still understand that it was positive before because I had symptoms, like coughing. However, I truly can't understand that why it is still positive in that I have no symptoms now. (P4)

\section{Subtheme 2 Panic Caused by Divergent Opinions on the Outcome of COVID-19}

Many participants (P1, P4, and P10) reported that individual differences in the outcome of COVID-19 often made them afraid of becoming severely ill patients. As confirmed cases, they were very worried that they might become permanent carriers of the virus or that they would relapse in the future. Some patients were obsessed with searching for information online and listening to rumours from people around them to obtain answers to the uncertainty. Excessive information involvement aggravated inner panic. As P1 stated:

I learned that there was someone who was in similar condition as me who suddenly passed away because of COVID-19. In that case, I began to worry about whether I could survive. (P1)

A massive amount of information has become a doubleedged sword in the current era of highly developed networks. The network is very convenient for information transparency and health information communication, but it also sharpens the sense of uncertainty because people lack the ability to judge massive amounts of unselected information. P10 and P4 provide examples:

The Internet is saying that humans currently have no effective treatment for this viral infection. Many infected people became positive again after being discharged from the hospital. Someone said that the virus could not be completely killed, and it just turned to sleep. These viruses may wake up at some point in the future. Hearing these words, I had pretty large psychological pressure. (P10)

When the doctor told me that I was diagnosed with COVID19, I really broke down. Looking at the sky, I was thinking that I might never see this beautiful sky again. I arranged everything after my possible death to my wife. Because it was my worst time with severe symptoms, I could not walk. I just felt like I was going to die. (P4) 


\section{Theme 2 Ethical Dilemmas Facing the Family and Society}

This disease showed a "clustering epidemic" pattern, and family-clustered onset was the main characteristic. Familyism is the main feature of traditional Chinese culture. Family members generally maintain close relationships and frequent contacts. COVID-19 infection caused some patients to fall into ethical dilemmas when facing their families. The high contagiousness of the virus in the population also made them worry about whether others would accept them after they returned to society.

\section{Subtheme I Feelings of Guilt and Self-Blame When Facing Family}

A sense of guilt and regret was very common in the participants, especially when they talked about their families. For example, some patients expressed their regret for not having taken sufficient precautions beforehand. The first person who was infected with the virus in the family often felt guilt and self-blame, especially when the virus was passed from him/her to the other family members. Participant 1, who infected her daughter during isolation at home, said:

My daughter reminded me to be careful and that I should keep a certain distance from other family members. I blamed myself for passing the virus to my daughter. It was me who was not paying enough attention to it. I really felt regretful that my consciousness on preventing it was even not as strong as a child. (P1)

After a confirmed COVID-19 diagnosis, participants cared about their own health status and follow-up treatments, but most patients were most concerned about the possibility of passing the virus to someone in a close relationship, especially their families. It generally evoked their sense of responsibility to keep themselves isolated from others in the suspected stage. Sometimes they would also worry about negative impacts on their families due to their temporary loss of their family role and function. Fear of infecting family members became their main psychological burden, and their inability to perform the family role and functions further increased their self-blame. As P10 and P3 described:

I dare not go home. I actually dare not approach my newborn child and family. I hope I can stay outside as long as possible. Even if I recover, I think I still have to isolate myself from my family after I go home. I am worried that when I get close to my child, I may bring danger to her. (P10)

I'm the backbone of my family. My parents are already 68 years old, and my child was in primary school. In such situations, my core idea is that I couldn't become a critically ill patient. I asked my wife and child to stay at my parents' house. Then, I prepared to go further away to be quarantined. I want to avoid infecting them and avoid more infections of others. (P3)

\section{Subtheme 2 Dual Role Conflict Between Living and Dead Kinsfolk}

Because of the "clustering epidemic" of COVID-19, many members of the same family endured isolation and treatment. Some patients unfortunately died during this time because of severe symptoms. For the bereaved, the appropriate method to convey the message of the death of their loved ones who were treated together to the living relatives resulted in an ethical dilemma. They also felt guilty for not being able to give the deceased a timely funeral. However, they had to bear the grief of bereavement alone and the guilt of concealing information to avoid letting their relatives bear the pain of losing their loved ones. P5 and his wife were hospitalized with COVID-19, but his wife passed away due to severe symptoms. While bearing the pain of losing his wife, he lied to his son that his wife was alive.

I have not told my son about the death of my wife. I really do not know how to speak about it. I cannot predict his reaction. Only when I go back will I find some time to talk to him slowly. (P5)

P6 learned that his father, who was also diagnosed with COVID-19, had passed away. Worried that his elderly mother would not be able to bear the pain of losing her partner, he chose to lie to his mother that his father was still receiving treatment. He said the following:

My Mom always asked: How is your father? I said that he was still under treatment and it would take some time to get out. As a son, I could only bear it alone. I could only tell her slowly after being discharged from the hospital. (P7)

\section{Subtheme 3 Worries About Rejection After Returning to Society}

Due to the contagious nature of the disease and the uncertainty of its outcome, many patients (P1, P4, and P9) could not confirm whether they remained contagious and would 
suffer relapse after leaving the hospital. They were also worried that others may not accept them after they completed isolation and treatment and returned to work. As P1 and P9 quoted:

How will other people who have never been infected with COVID-19 see me? How should I perform my communication job in the future? People who have never been infected will more or less be afraid of someone like me. Maybe they will be afraid to contact and communicate with me. It means that I can't be what I was like before, being confident and normal when faced with other people. (P1)

P9 was hospitalized for 50 days. She was full of worries when she talked about her life after discharge.

After going out, you have to contact relatives, colleagues, and friends. This will definitely be a big trouble. At least I will not meet with them in two months after going out. I will not have in-depth contact with them. It is hard to say how others think of you and whether they are afraid of you. This is human nature. (P9)

\section{Subtheme 4 Attitude Towards Doctor-Patient Relationships}

The doctor-patient relationship in China has become increasingly tense in recent years and came to an "irreconcilable edge". Vicious criminal cases of "patient hurts medical staff" appeared frequently in the news. The frequency of these events has led to a very fragile relationship between Chinese doctors and patients and a lack of mutual trust. ${ }^{18}$ We specifically examined participants' perspectives on doctor-patient relationships based on their experiences with COVID-19. Most participants expressed positive attitudes towards it, including understanding, support and appreciation. As P3 stated:

I kept my positive attitudes on doctors. As a group of upright people in society, I know they originally are positive. I'm grateful from the bottom of my heart. (P3)

Some of the participants changed their previous negative impressions of medical professionals to positive impressions because of their experiences during this period:

I think the doctor-patient relationship changed a lot. Although attitudes of some people on the relationship were still not so good, I felt most turned better. Patients were not easily satisfied with what doctors or nurses did. However, they were paid too much during this time. They are stuck inside of the protective equipment. It was unbearable not to eat and drink for a long time. (P8)

Participant 9 indicated that media coverage may be key to guiding people's thoughts about doctor-patient relationships. The public media must report objectively to promote a healthy development of the relationship.

I think the doctor-patient relationship is just guided by the reports, no matter whether the epidemic happened. Both good and bad doctors exist in the world. The profession of a doctor like you is quite similar to the profession of a teacher like me. It's just because the COVID-19 outbreak happened. It seems like the relationship becomes better because medical staff did lots of things that deserved positive reports and were enlarged. It's just because it is being reported more; it will change back afterwards. (P9)

\section{Theme 3 Resources to Cope with COVID-19}

Ten participants were interviewed in this study. Two participants of them (P5 and P6) experienced bereavement, and two participants of them ( $\mathrm{P} 3$ and $\mathrm{P} 4$ ) survived despite nearly fatal complications. When talking about how they handled the darkest moments of life, they mentioned the inner strength and resources that supported them.

\section{Subtheme I Personal Belief}

A belief is an attitude that something is true or that some proposition about the world is true. Philosophers in epistemology use the term "belief" to refer to attitudes about the world that may be true or false. Many participants (P3, P4, P6, and P9) in the study mentioned the important role of belief in the fight against COVID-19. The personal belief of participant 3 was derived from her strong desire to survive. She said, "as long as I am still breathing, I have hope." Her strong desire to survive also resulted in trust in the medical staff:

I always believe in them. There is no doctor who does not want his patients to be well. Just like parents, I hope that my children will always have this belief in my mind, and I am also very optimistic. (P3)

The belief of participant 6 is derived from Taoism in traditional Chinese culture: "Fortune and disaster are interdependent and transform each other." As he stated:

We must learn to look at problems dialectically. Everything has an accumulation process, and it will change at a certain 
stage. God is fair, if he gives you this, he will take your other away, right? This is a natural law. (P6)

The belief of participant 9 was derived from the fatalistic view of causal reincarnation. Fatalism facilitated her ability to adjust her mentality quickly and devote herself to actively helping others during treatment.

Whether you are doing things or speaking, you must stay away from "evil"; otherwise, there must be retribution. I think it's the faith made me feel comfortable from inner heart and conscience. I think it's impossible for someone with faith to have a sense of helplessness ...... The lights in the cabin are all on for 24 hours, just like during the day. I bought 1000 face masks and donated them to patients. Since I started this, many patients have donated things to the hospital. For some medical staff, things are really hard, so I drew some pictures for them. They are very happy. (P9)

\section{Subtheme 2 Responsibility to the Family}

Familialism or familism is an ideology that prioritizes family. This ideology manifests as prioritizing the needs of the family higher than the needs of individuals. ${ }^{19}$ Chinese people are traditionally supreme in familialism. Almost every participant mentioned that they worried most about their family after they were diagnosed but not themselves. As the only child in the family, participant 2 had 70-year-old parents and a 2-year-old son. He always emphasized "I cannot go wrong". This sense of responsibility prompted him to maintain rational thinking and actively implement epidemic prevention measures.

I go to quarantine alone every night. My core idea is that I cannot become severely ill because my family cannot do without my care. (P2)

Participant 5 suffered the pain of losing his wife and insisted on active treatment to care for his son and deal with the funeral affairs of his deceased wife and father. As he described:

I told myself that I was already sorry for my wife, and I had no choice but to raise a child. I want to live. Because my wife's funeral affairs and father's funeral affairs have to be handled by me, I must go back alive and healthy. My mother and my son are waiting for me. (P5)

\section{Subtheme 3 Support from Others}

Almost all patients mentioned that they received help from all sides in their struggle with COVID-19. Positive encouragement, kind words, and professional service often helped the patients overcome their anxiety and panic. This support also boosted their confidence in overcoming the disease. Participants mostly referred to their perceived support from families. As P7 stated:

Both my wife and I were infected. We started treatment in different hospitals. We encouraged and supported each other. A month later, we were assigned to the same ward. On the day of the meeting, I was very excited and very happy. Our mutual company makes hospital life a happy experience. (P7)

Medical staff offered professional support to patients for their physical, mental and social health. Sometimes their existence itself was a great comfort and support for patients, even without the performance of any special acts.

All doctors, even all people wearing protective clothing, are regarded as life savers in the patients' eyes. As long as the patients caught them, they would keep asking, and sometimes the same question would be asked 10 times. In fact, doctors were not able to solve patients' problems at all. However, they felt better if a doctor listened to them with patience. Some patients would cry or make trouble here, but some doctors were good at appeasing. Doctors really provide different psychological comfort to patients. (P9)

Participants also mentioned other sources of support, such as the government and companies. As P4 and P5 stated:

I followed the decision of the government, went to the quarantine spot, and then the mobile cabin hospital, next, this hospital. Now, I have already recovered. I really appreciate it. (P4)

Since my wife and I were both infected, our company donated more than 100,000 to us. (P5)

\section{Theme 4 Event-Related Growth Experience}

Misfortune or disaster cause chaos and harm, but these situations also become an opportunity to promote growth. ${ }^{20}$ Traditional Chinese culture often assigns positive meaning to suffering and uses the philosophy of "bearing hardships, we are the best" to inspire people to cope with setbacks in life. The dialectical thinking of 
mutual transformation of blessings and misfortunes enlightens people to actively construct suffering in life. The participants in this study also mentioned positive experiences obtained from this incident, including changes in priorities, personal strength enhancement in the trauma narrative, obtaining new insights into life, and gratitude.

\section{Subtheme I Changes in Priorities}

Priority is a sense of what is most important in life, which is one of the elements of a changed life philosophy that individuals may experience as posttraumatic growth. After experiencing such a life-threatening disease, participants stated that they perceived the fragility and preciousness of life and health. "Nothing big beyond life or death" became the consensus of many participants. Maintaining and promoting health became the top priority in their lives. Some participants began to plan actions to adjust their lifestyles in the future. Participants 1 and 7 were examples:

I used to be a workaholic and demanded more of myself. This experience has taught me a lot. The things I valued in the past are not worth so much. My own happiness and comfort are the most important. (P1)

I plan to get rid of my previous bad habits, such as skipping breakfast in the morning and staying up late at night. In the future, I will work and rest regularly and insist on going to bed and getting up early. (P7)

Participants 2 and 10 indicated that they used to pay more attention to external things. This experience made them realize the importance of family. They said that they cherished their families more and were trying to get along better with them in the future. For example:

The biggest change for me was that I personally may pay more attention to family. There were some gaps between my wife and I. During this time, we had gradually let go of some personal prejudices, and our relationship had improved a lot. I had also invested more in the education of my son. (P2)

\section{Subtheme 2 Obtain Strength from Personal Trauma Narratives}

The COVID-19 epidemic was a traumatic event, and its suddenness, unexpectedness, uncertainty of the outcome, and high group infectivity obviously traumatized patients. "Trauma" relates to a person's survival experience in a universal sense. During the interview, many participants told stories about their illnesses in large sections and gradually expanded to other important moments in their lives. This traumatic experience also evoked their memories of past traumas. The interviewer's careful listening and feedback enabled the participants to complete the affirmation of self-excellent qualities and personal beliefs and obtain the power to overcome trauma.

Based on the current experience of illness, participant 7 was reminded of her experience of being saved from a serious illness in the past. This memory inspired her to cherish her life, be grateful to the rescuer and construct a positive meaning of her own life.

There were two major events in my life experience. The first time, my mother saved me when I was seriously ill. This is the second time that your medical staff rescued me. To sum up, everything is trivial except life and death. Body and life are the most important. (P7)

Participant 3's eldest daughter played an important role in obtaining rescue opportunities and fighting COVID-19. What mattered most to participant 7 was her guidance to her daughter's values and her pride as a mother. She interpreted her daughter's care for herself as the result of her good education, which strengthened her identification with her own wisdom. As participant 3 noted:

I am also a qualified mother. I have always been very open to my two daughters and gave them a lot of love. I have always taught them to be kind and generous. This time, it was the eldest daughter who saved my life, and the younger daughter did not blame me for being infected. (P3)

Participant 5 expressed nostalgia for his wife through the narrative of his past life. The processes of narrative expression and being heard allowed him to gradually return to reality.

My wife was very hardworking and liked to save money. She was very careful. She was responsible for everything in our family. Originally, I told her that you live 80 years old and I live 81 years old. We meet to grow old together. Now I am alone, and I can dream of her every day. (P5)

\section{Subtheme 3 Gratitude}

Because they received so much help from society in this epidemic, the participants were filled with gratitude. Most of the participants expressed their strong sense of gratitude. They were grateful for the free treatment provided by the country and government, for the dedication of the medical staff, and for mutual help among people. The 
feeling of gratitude also made them realize that they were being cared for and valued, and they obtained inner peace. The following statements are two examples:

First, I want to thank the government for providing free medical care. Second, I want to thank the medical staff. They left their homes and came here during the Spring Festival. They paid a great price. When we lie down for treatment, we must first be in a good mood to be worthy of their efforts. (P3)

I was transferred to three hospitals and wanted to say "thank you" heartily to all the medical staff. If it were not for such a group of lovely people, I think it would be impossible for me to recover so well and so quickly. (P10)

Gratitude for help from others also made some patients think of giving back to society. As participant 8 said:

My wife and I were in the same ward. Both of us recovered. I am truly grateful and moved. I heard that the vaccine needs volunteers. I want my son to be a volunteer to contribute to the epidemic, to society, and the country. (P8)

Participant 10 also expressed her gratitude to the medical staff. She expected that her daughter would choose to study medicine in the future because of the professional altruism of medical staff:

I have been thinking these days, after my daughter grows up, if her parents can interfere with her wishes, I really want her to study medicine. Because I hope she will become a helpful and valuable person to society. (P10)

\section{Discussion}

This qualitative study examined the experiences of patients with COVID-19 in a mobile cabin hospital in Wuhan and primarily focused on their psychological adaptation processes and coping resources.

Consistent with many other studies, ${ }^{14,21,22}$ the participants in the present study also experienced stress, anxiety, and panic during the initial stage of the COVID-19 outbreak. However, the present study found that some participants also experienced more complicated emotions, such as self-doubt and guilt. Some of them were caught in profound ethical dilemmas. Because Wuhan was the first city to experience the epidemic, it received assistance from medical staff across the country to fight against the disease. A total of 42,000 medical, mental health and psychological staff from all over the country were enlisted to support the population, staff and patients in dealing with the epidemic in Hubei Province, especially Wuhan. $^{23}$ This support provided patients with safety guarantees and social support. Therefore, the support of medical staff from across the country and the gradual control of the epidemic allowed patients to experience some positive emotions, such as gratitude to medical staff and the government. The current study found that the patient's personal beliefs and sense of responsibility were important resources in their fight against COVID19. Gratitude also helped some patients reduce stress and anxiety.

Crisis is a double-edged sword. Crises cause chaos and harm but also become an opportunity to promote growth. Although some studies examined the negative psychological impact of COVID-19, fewer studies focused on how positive outcomes may occur despite adversities. ${ }^{24}$ Posttraumatic growth (PTG) refers to a positive adaptation process in which people re-evaluate their traumatic experience, and it is largely overlooked in scholarly literature. ${ }^{20}$ Traditional Chinese culture recognizes positive change as an outcome of traumatic events, such as Mencius, who allegedly stated: "When heaven is about to place a great responsibility on a great man, it always first frustrates his spirit and will." Most participants in the present study experienced event-related growth, such as changes in priorities, personal strength enhancement, obtaining new insights into life, and gratitude. The present study showed that the trauma of the epidemic often evoked memories of the participants' past experiences of fighting against adversity. These experiences became their resources to address their present difficulties. According to Nietzsche, "That which does not kill us makes us stronger". ${ }^{24}$ We found that participants preferred large sections of narratives, and the presence and communication of interviewers contributed to the positive construction of their growth experience. This finding further confirms that patients who experience sudden traumatic events are psychologically eager to be heard. They need to vent their inner emotions via self-disclosure to complete the reconstruction of selfpower.

As shown in previous studies, patients who were diagnosed with diseases that caused pandemics received more attention during the acute phase. ${ }^{25}$ China learned from the experience of handling the SARS and $\mathrm{H} 1 \mathrm{~N} 1$ pandemics many years ago. ${ }^{26,27}$ After the COVID-19 outbreak, special psychological and psychiatric services were fully implemented to address the COVID-19 crisis throughout 
the country. ${ }^{23}$ However, the findings from the present study revealed that some patients were fearful about the uncertainty of the future. Many patients had strong worries about adapting to social and family roles after discharge. They lacked sufficient confidence in returning to work and reintegrating into the crowd. The bereaved did not easily overcome the pain associated with the epidemic. Therefore, attention and interventions in patients with COVID-19 should not simply end with a negative nucleic acid test or discharge. Psychological reconstruction after trauma needs the continuous attention and support of psychosocial workers.

\section{Clinical Implications}

The literature shows that the pandemic exerted a substantial effect on the mental health of people worldwide, especially people who were diagnosed. ${ }^{28}$ Promoting patients' mental health and trauma integration are important tasks of mental health services. The findings of the present study have several clinical implications for strategies to facilitate improvements in the mental health of patients with different cultural backgrounds who are suffering from COVID-19. First, mental health providers should understand patients based on their experiences. Promoting the mental health of patients should be individual-centred and work at the system level of family and society. Second, everyone has the potential to grow. Focusing on patient resources and positive experiences after trauma are important ways to promote patients' mental homeostasis. Third, the personal narratives of people who experienced trauma may help them integrate the trauma. Experienced individuals are the best experts. Mental health providers must sometimes become learners who listen and accompany and provide immediate positive feedback to help patients achieve PTG. Fourth, humans' understanding of COVID-19 remains very limited. Many of the patients' uncertainties remain unexplainable. Some patients face multiple traumas, such as bereavement, and need further mental health services.

\section{Limitations}

The present study inevitably has some limitations. First, the study recruited patients only from a single COVID-19designated hospital in Wuhan, and it does not represent patients' experiences from other hospitals and areas. Second, challenges will emerge when these patients return to their homes and society. Whether they will demonstrate better adjustment or transform their PTG experience into action after discharge (such as interpersonal connections and altruistic acts) is not certain, and further longitudinal studies are needed.

\section{Acknowledgments}

We thank all of the persons who participated in this study and Guanggu Hospital.

\section{Funding}

This study was funded by a grant from the National Social Science Foundation (17ZDA327) to YHB.

\section{Disclosure}

The authors declare no potential conflicts of interest with respect to the research, authorship, and/or publication of this article.

\section{References}

1. Wang C, Horby PW, Hayden FG, Gao GF. A novel coronavirus outbreak of global health concern. Lancet. 2020;395 (10223):470-473. doi:10.1016/S0140-6736(20)30185-9

2. WHO. WHO Coronavirus disease (COVID-19) situation dashboard. 2021. Available from: https://covid19whoint/. Accessed June 17, 2021.

3. WHO. Coronavirus disease (COVID-19). 2021. Available from: https://wwwwhoint/emergencies/diseases/novel-coronavirus-2019/ question-and-answers-hub/q-a-detail/q-a-coronaviruses. Accessed June 17, 2021.

4. Sun C, Wu Q, Zhang C. Managing patients with COVID-19 infections: a first-hand experience from the Wuhan Mobile Cabin Hospital. Br J Gen Pract. 2020;70:229-230. doi:10.3399/ bjgp20X709529

5. Zhu W, Wang Y, Xiao K, et al. Establishing and managing a temporary coronavirus disease 2019 specialty hospital in Wuhan, China. Anesthesiology. 2020;132:1339-1345. doi:10.1097/ ALN.0000000000003299

6. Denckla CA, Gelaye B, Orlinsky L, Koenen KC. REACH for mental health in the COVID19 pandemic: an urgent call for public health action. Eur J Psychotraumatol. 2020;11:4. doi:10.1080/ 20008198.2020.1762995

7. Sun WX, Zhou Y, Chen WT, et al. Disclosure experience among COVID-19-confirmed patients in China: a qualitative study. J Clin Nurs. 2021;30:783-792. doi:10.1111/jocn.15616

8. Hossain MM, Sultana A, Purohit N. Mental health outcomes of quarantine and isolation for infection prevention: a systematic umbrella review of the global evidence. Epidemiol Health. 2020;42. doi:10.4178/epih.e2020038

9. Yip PSF, Cheung YT, Chau PH, Law YW. The impact of epidemic outbreak the case of Severe Acute Respiratory Syndrome (SARS) and suicide among older adults in Hong Kong. Crisis. 2010;31:86-92. doi:10.1027/0227-5910/a000015

10. Usher K, Bhullar N, Jackson D. Life in the pandemic: social isolation and mental health. $J$ Clin Nurs. 2020;29(15-16):2756-2757. doi:10.1111/jocn. 15290

11. Hawryluck L, Gold WL, Robinson S, Pogorski S, Galea S, Styra R. SARS control and psychological effects of quarantine, Toronto, Canada. Emerg Infect Dis. 2004;10:1206-1212. doi:10.3201/ eid1007.030703 
12. Chua SE, Cheung V, McAlonan GM, et al. Stress and psychological impact on SARS patients during the outbreak. Can J Psychiatry. 2004;49:385-390. doi:10.1177/070674370404900607

13. Brown C, Peck S, Humphreys J, et al. COVID-19 lessons: the alignment of palliative medicine and trauma-informed care. J Pain Symptom Manag. 2020;60:E26-E30. doi:10.1016/j. jpainsymman.2020.05.014

14. Freedland KE, Dew MA, Sarwer DB, et al. Health psychology in the time of COVID-19. Health Psychol. 2020;39:1021-1025. doi:10.1037/hea0001049

15. China NHCo. New coronavirus pneumonia diagnosis and treatment plan (trial version 7). 2020. http://wwwnhcgoven/yzygj/s7653p/ $202003 / 46$ c 9294 a 7 d fe 4 cef 80 d c 7 f5 912 eb $1989 /$ fi les / ce3e6945832a438eaae415350a8ce964pdf. Accessed June 17, 2021.

16. De Visser R, Smith JA. Mister in-between - a case study of, masculine identity and health-related behaviour. $J$ Health Psychol. 2006;11:685-695. doi:10.1177/1359105306066624

17. $\mathrm{SJaO} \mathrm{M}$. Interpretative phenomenological analysis. In: Smith JA, Osborn M, editors. Qualitative Psychology: A Practical Guide to Research Methods. London: SAGE; 2008:53-80.

18. Zhou M, Zhao LD, Campy KS, Wang S. Changing of China's health policy and doctor-patient relationship: 1949-2016. Health Policy Technol. 2017;6:358-367. doi:10.1016/j.hlpt.2017.05.002

19. Pertierra R. Transformation of the Intimate and the public in Asian modernity. Int $J$ Asian Stud. 2018;15:119-121. doi:10.1017/ S1479591417000225

20. Calhoun LG, Tedeschi RG. The foundations of posttraumatic growth: new considerations. Psychol Inq. 2004;15:93-102. doi:10.1207/ s15327965pli1501_03
21. Rajkumar RP. COVID-19 and mental health: a review of the existing literature. Asian J Psychiatr. 2020;52:102066.

22. Wang CY, Pan RY, Wan XY, et al. Immediate psychological responses and associated factors during the initial stage of the 2019 Coronavirus Disease (COVID-19) epidemic among the general population in China. Int $J$ Environ Res Public Health. 2020;17:25. doi:10.3390/ijerph17196951

23. Wang Y, Zhao X, Feng Q, Liu L, Yao Y, Shi J. Psychological assistance during the coronavirus disease 2019 outbreak in China. J Health Psychol. 2020;25:733-737. doi:10.1177/1359105320919177

24. Tamiolaki A, Kalaitzaki AE. "That which does not kill us, makes us stronger": COVID-19 and posttraumatic growth. Psychiatry Res. 2020;289:113044. doi:10.1016/j.psychres.2020.113044

25. Mak WWS, Law RW, Woo J, Cheung FM, Lee D. Social support and psychological adjustment to SARS: the mediating role of self-care self-efficacy. Psychol Health. 2009;24:161-174. doi:10.1080/ 08870440701447649

26. Torales J, O’Higgins M, Castaldelli-Maia JM, Ventriglio A. The outbreak of COVID-19 coronavirus and its impact on global mental health. Int $J$ Soc Psychiatry. 2020;66:317-320. doi:10.1177/ 0020764020915212

27. Yang YS, Peng FJ, Wang RS, et al. The deadly coronaviruses: the 2003 SARS pandemic and the 2020 novel coronavirus epidemic in China. J Autoimmun. 2020;109:16. doi:10.1016/j.jaut.2020.102434

28. Fernandez-Abascal EG, Martin-Diaz MD. Longitudinal study on affect, psychological well-being, depression, mental and physical health, prior to and during the COVID-19 pandemic in Spain. Pers Individ Dif. 2021;172:110591. doi:10.1016/j.paid.2020.110591
Psychology Research and Behavior Management

\section{Publish your work in this journal}

Psychology Research and Behavior Management is an international, peer-reviewed, open access journal focusing on the science of psychology and its application in behavior management to develop improved outcomes in the clinical, educational, sports and business arenas. Specific topics covered in the journal include: Neuroscience, memory and decision making; Behavior modification and management; Clinical applications; Business and sports performance management; Social and developmental studies; Animal studies. The manuscript management system is completely online and includes a very quick and fair peer-review system, which is all easy to use. Visit http://www. dovepress.com/testimonials.php to read real quotes from published authors. 